Korean J. Math. 20 (2012), No. 4, pp. 493-505

http://dx.doi.org/10.11568/kjm.2012.20.4.493

\title{
A NEW AGE IN MATHEMATICS EDUCATION IN THE U.S.: INTERPRETING THE COMMON CORE STATE STANDARDS FOR MATHEMATICS
}

\author{
Jihwa Noh, Nan HuH* And Ho-Kyoung Ko
}

\begin{abstract}
For the first time ever in its history, the United States has a national version for $\mathrm{K}-12$ mathematics programs, the Common Core State Standards for Mathematics. Since its final version appeared in 2010 in the United States, the Common Core State Standards have started getting much attention from the Korean mathematics and mathematics education communities. Although attempts have been made to translate the original text of the standards, the information such as the paradigm shift that led to the development of the standards, design principles and a comparison with the NCTM Standards would aid understating the standards in the intended way and avoiding unnecessary confusion.
\end{abstract}

\section{A paradigm shift}

Since the National Council of Teachers of Mathematics (NCTM)'s 1989 Standards, Curriculum and Evaluation Standards for School Mathematics ([1]), which provided a major impetus for states and school districts to develop curriculum guidelines, states started writing curriculum standards. According to a U.S. Department of Educations 2009

Received November 6, 2012. Revised December 13, 2012. Accepted December 15, 2012.

2010 Mathematics Subject Classification: 97A30.

Key words and phrases: curriculum standards, Common Core State Standards, NCTM Standards.

*Corresponding author.

(c) The Kangwon-Kyungki Mathematical Society, 2012.

This is an Open Access article distributed under the terms of the Creative commons Attribution Non-Conercial License (http://creativecommons.org/licenses/bync/3.0/) which permits unrestricted non-commercial use, distribution and reproduction in any medium, provided the original work is properly cited. 
report ([2]), as the 1990s progressed, all but one of the states developed their own statewide standards; In the early twenty-first century, all states developed tests to measure student performance, and; By 2007, all states have developed state-level curriculum standards. But while all states have developed and implemented standards, it has been noted that these standards lack consensus across states ([3]). Also, results from the Third International Mathematics and Science Study (TIMSS) still show that U.S. eighth and twelfth graders do not do well by international standards-ranking below average in both grades and, in fact, near the bottom of the international rankings on a mathematics literacy test at the end of high school. Even their best students in mathematics taking an advanced mathematics test do not fare well against their counterparts in the other countries ([4], [5], [6]).

As an attempt in addressing this challenge, in 2007 the National Governors Association (NGA) and the Council of Chief State School Officers (CCSSO) discussed the idea of developing common standards, and in the spring of 2009, the Common Core State Standards Initiative (CCSSI) was launched with 48 states, the District of Columbia, and two territories coming together under the auspices of NGA and CCSSO to develop a common core of state $\mathrm{K}-12$ English language arts and mathematics standards. In their analysis of the 2007 national assessment scores corresponding to state standards for proficient performance in 8th-grade mathematics, CCSSI has noted that in many cases, state curriculum standards do not reflect the knowledge and skills needed for success after high school, either in further education or in a job, and as its result, developed the high school math and college readiness document in 2009 ([7]). The Common Core State Standards for Mathematics (CCSSM), as part of the Common Core State Standards Initiative, have been developed to provide clarity on what students are expected to learn, in an effort to make the U.S. mathematics education more consistent across states and to guide teachers in preparing students for the challenges of the workplace or postsecondary study. Its final draft, which came out in 2010, provides a detailed description of content expectations and mathematical practices for $\mathrm{K}-12$ mathematics programs. CCSSM has been adopted by 45 states, the District of Columbia and three territories (Guam, American Samoa Islands and US Virgin Islands) ([8]). 


\section{The work}

To develop CCSSM, CCSSI convened a math work team including about 60 teachers, education researchers, mathematicians and policy makers. The math team started by writing narrative progressions of topics across grade levels in $\mathrm{K}-8$ and high school. Grade level standards were sent out for review with states, feedback committee, and national organizations during fall 2009 and spring 2010. A public comment draft was out in March 2010. Final draft came out in June 2, 2010. CCSSI indicated that their work was built and reflected upon the work based on the influential NCTM Standards movement ([8]). Other important considerations that informed this work included the following:

Number sense in early grades. Internationally high achieving countries concentrate the early learning of mathematics on the number, measurement, and geometry strands with less emphasis on data analysis and little exposure to algebra ([9]). The Natioanl Research Council (NRC) ([10]) suggestes that early childhood settings should concentrate on number (which includes whole number, operations, and relations) and geometry, spatial relations, and measurement, with more mathematics learning time devoted to number than to other topics.

Focused curriculum. U.S. mathematics curriculum is often criticized as "a mile wide and an inch deep," meaning that their curriculum covers way too many topics in each grade but little in depth. Also, it has been repeatedly documented that the mathematics concepts in U.S. textbooks are often weak, the presentation becomes more mechanical than is ideal ([9], [11]). The math team reviewed mathematics textbooks of high performing countries such as South Korea, Singapore and Hong Kong. Their review noted that on average a high performing country would have 6 topics per grade level in its complete curriculum. The math team incorporated the mathematics topics that were intended at each grade by at least two thirds of those high performing countries. High performing countries were determined by looking at statistically significant differences in 8th grade scores on 1995 TIMMS.

Coherent curriculum. A detailed analysis of the grade placement of mathematics learning goals across all state-level curriculum standards was conducted in 2005 ([3]). The results of the analysis documented that states content standards are hugely diverse and confusing due to 
varied grade-level mathematics curriculum expectations and inconsistent placements.

\section{Structure of CCSSM}

3.1. Content standards. Content standards define what students should understand and be able to do. Content standards for kindergarten through eighth grade are presented by grade level and organized into domains (such as Operations \& Algebraic Thinking, Expressions \& Equations, and Geometry) that progress over several grades. Grade introductions give 2-4 focal points at each grade level. High school standards are presented by conceptual theme (Number \& Quantity, Algebra, Functions, Modelling, Geometry, and Statistics \& Probability). High School standards indicate material necessary for students to take advanced mathematics courses in high school such as calculus, advanced statistics, or discrete mathematics, and to be prepared for science, technology, engineering, and mathematics coursework in college. In each domain or conceptual theme, groups of related standards are clustered. A brief overview of the content progression is displayed in Figure 1.

3.2. Standards for mathematical practices. The mathematical practices standards describe practices that pervade doing mathematics at all grade levels:

- Make sense of problems and persevere in solving them.

- Reason abstractly and quantitatively.

- Construct viable arguments and critique the reasoning of others.

- Model with mathematics.

- Use appropriate tools strategically.

- Attend to precision.

- Look for and make use of structure.

- Look for and express regularity in repeated reasoning.

These are not pedagogical practices but are habits of mind that mathematicians use at work and mathematically expert students appear to have. They describe an array of expertise that both students and teachers need to develop. That is, students should develop them as they learn mathematics and teachers should use them in their instruction to help foster reasoning and sense-making in mathematics. The mathematical practices standards include thinking processes as well as dispositions 


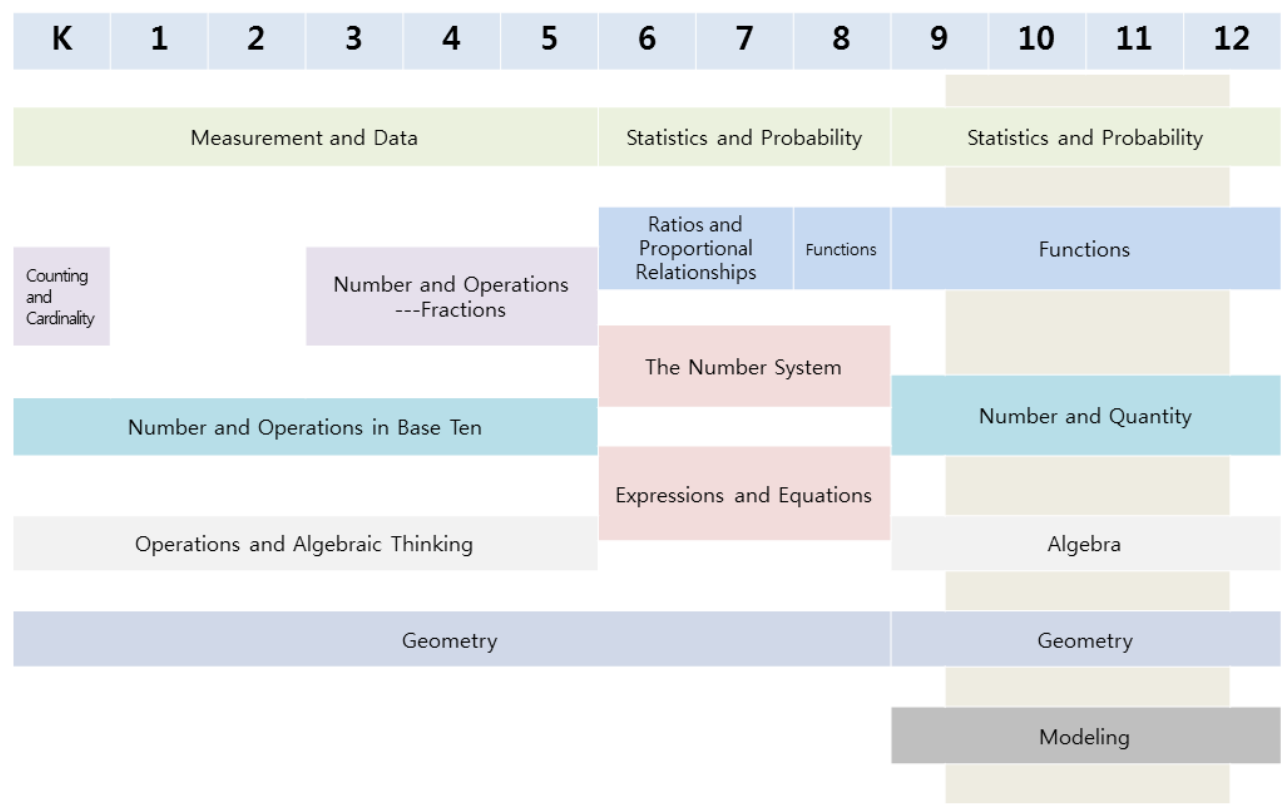

FiguRE 1. Progression of CCSSM's content standards.

that need to be developed to assure a deep understanding of mathematics. It is noted that the origins of these ideas are NCTM Process standards ([12]) and the NRC's report Adding It Up ([13]).

\section{Design principles for CCSSM}

4.1. Focus. It is attending to fewer topics in greater depth at any given grade level, giving teachers and students time to complete that grades learning. For example, 4 out of 5 domains in $\mathrm{K}-5$ deal with numbers and operations. Many standards in the other domains support this focus. CCSSM include fewer topics per grade, but overall they are ambitious goals.

The mile-wide inch-deep problem looks different in high school. In earlier grades it is a matter of having too many topics. In high school it is a matter of having too many separately memorized techniques, with no overall understanding of the structure to tie them altogether. So, narrowing and deepening the curriculum is not so much a matter of eliminating topics, as seeing the structure that ties them together. The 
following problems illustrate how this can be achieved regarding the Algebra standard A-SSE: Seeing Structure in Expressions:

- You just won a 5.0 mega-pixel digital camera for participating in an online promotion. According to a web review this particular model is currently valued at 500 dollars and depreciates according to the formula $C=500(0.8)$ per year (since 2010). Which of the following is true?

(a) The camera loses value at a rate of $1.8 \%$ per month.

(b) The camera loses value at a rate of $80 \%$ per year.

(c) The camera loses value at a rate of exactly $10 \%$ every six months.

(d) The camera loses value at a continuous rate of $20 \%$ per year.

In this problem, question form pulls together various skills needed in manipulating exponential functions, without asking for any particular skill in isolation.

- Suppose $P$ and $Q$ give the sizes of two different animal populations, where $Q>P$. Which expression in each of the following pairs is larger?

(a) $P+Q$ and $2 P$

(b) $P /(P+Q)$ and $(P+Q) / 2$

In this problem, context allows for pulling together several abstracts and potentially disconnected arrangements for symbols.

4.2. Coherence. This is attending to the structure of mathematics and the natural pathways through that structure, where "natural" means taking into account both the imperatives of logic and the imperatives of cognitive development in designing the sequence of ideas. That is, mathematical progression plus learning progression. In addition, CCSSM regard "big ideas" not as a zooming-out to get a picture but as many important small ideas with different weights. Coherence flows from focus. Figure 2 presents how algebra-related topics are coherently progressed across grade levels.

In recent years, the U.S. school districts have been moving algebra into the middle school and give ninth grade credit. In CCSSM, eight-grade students are expected to learn properties of operations, similarity, ratio and proportional relationships, and rational number system as a ramp up to high school algebra, and focus on linear equations and functions, which include but are not limited to: working with radicals and integer 


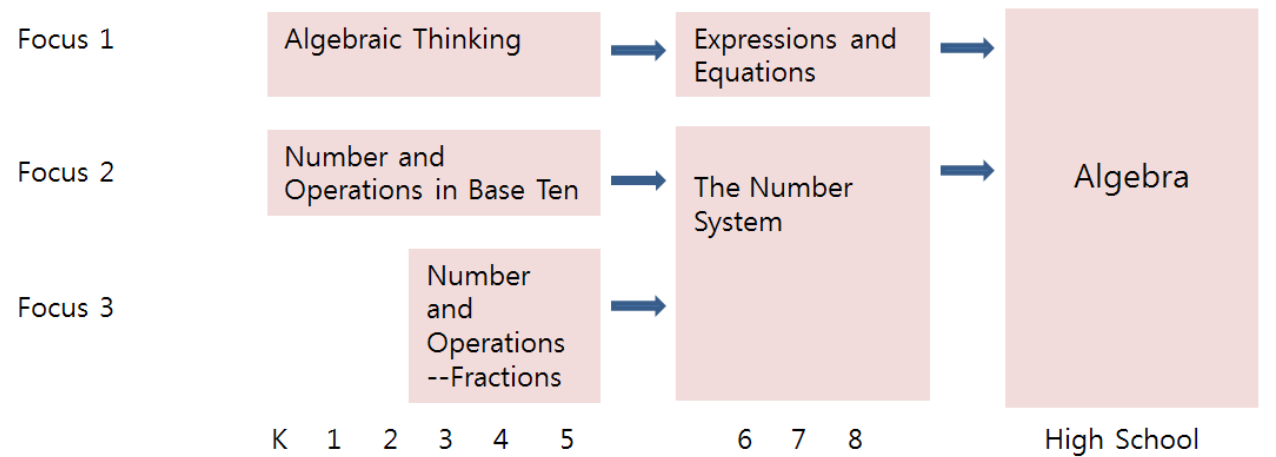

FiguRE 2. Progression of algebra-related domains

exponents; understanding the connections between proportional relationships, lines, and linear equations; analysing and solve linear equations and pairs of simultaneous linear equations; defining, evaluating, and comparing functions, and; using functions to model relationships between quantities. These learning areas help equip students for early high school algebra which centers around seeing structure in expressions (that is, interpreting the structure of expressions and writing expressions in equivalent forms to solve problems) and reasoning with equations and inequalities (more specifically, being able to understand solving equations as a process of reasoning and explain the reasoning; solve equations and inequalities in one variable; solve systems of equations, and; represent and solve equations and inequalities graphically).

4.3. Rigor. The Rigor principle is balancing conceptual understanding, procedural fluency, and meaningful applications of mathematics. To achieve this principle, CCSSM define learning expectations in the three forms. Regarding conceptual understanding, there are learning expectations for which students are expected to demonstrate their understanding of relating concepts. For example,

- Grade 1. Understand and apply properties of operations and the relationship between addition and subtraction.

- Grade 4. Understand decimal notation for fractions, and compare decimal fractions.

- Grade 8. Understand the connections between proportional relationships, lines, and linear equations. 
- High School: Understand solving equations as a process of reasoning and explain the reasoning

Some learning expectations are defined in ways that ask students to achieve procedural fluency. For examples,

- Grade 1. Add and subtract within 20.

- Grade 3. Fluently multiply and divide within 100, using strategies such as the relationship between multiplication and division. By the end of Grade 3, know from memory all products of two one-digit numbers.

- Grade 6. Fluently divide multi-digit numbers using the standard algorithm.

- High School: Write arithmetic and geometric sequences both recursively and with an explicit formula, use them to model situations, and translate between the two forms.

Also, there are learning expectations requiring applications of mathematics. Learning expectations in this regard typically call for learning contexts where students solve real-life or complex mathematics problems. For example, Grade 7. Solve multi-step real-life and mathematical problems posed with positive and negative rational numbers in any form (whole numbers, fractions, and decimals), using tools strategically. Apply properties of operations to calculate with numbers in any form; convert between forms as appropriate; and assess the reasonableness of answers using mental computation and estimation strategies. In high school, application of mathematics is best represented by the modelling standards: Model with mathematical modelling cycle (Figure 3). The modelling standards appear throughout other high school standards indicated by a star symbol, not as a collection of isolated topics. For example, "Develop a probability distribution for a random variable defined for a sample space in which probabilities are assigned empirically; find the expected value" is listed under the Statistics \& Probability strand.

\section{CCSSM in comparison to the NCTM's standards}

5.1. Purposes. CCSSM and NCTM standards ([12]) documents have a shared vision based on the need for a focused and coherent curriculum, a balance between mathematical understanding and procedural skills, and an emphasis on process skills. While the documents share a vision, they 


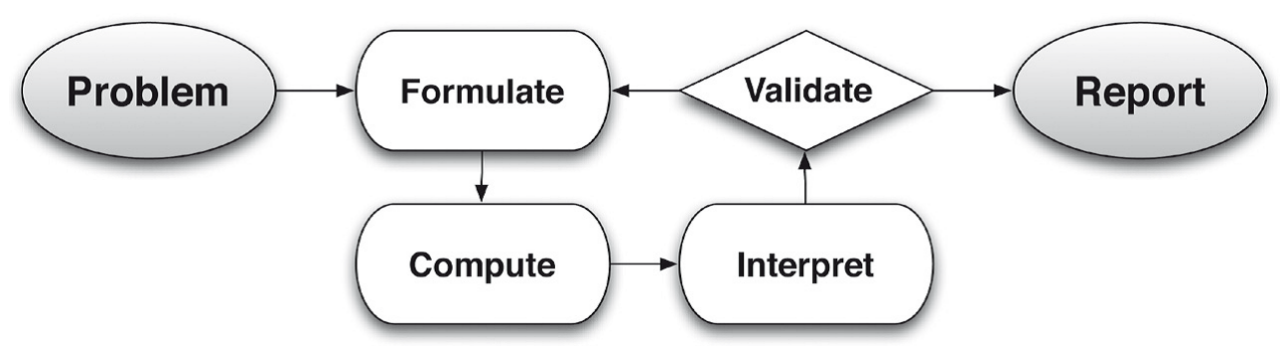

FIGURE 3. Modelling cycle diagram illustrated in CCSSI $[8$, p. 72$]$

do serve quite different purposes. NCTM Standards put forth a broad vision for school mathematics, including many examples and advice for implementation, while CCSSM provides a detailed set of grade-by-grade standards that can be immediately adopted as a state curriculum. Different purposes for each document led to differences in their levels of specificity. CCSSM lay out a vision for what all students need to master to be ready for credit-bearing college mathematics courses without remediation, while NCTM's Standards provide recommendations for all students and the most important mathematical topics for each grade band. A NCTM's later publication, Focal Points ([14]), more clearly describes connections among topics, whereas CCSSM provide greater detail and specificity regarding learning expectations.

5.2. Content placements. The content comparison is not as easy to make, because CCSSM are not divided between the same strands as NCTM. In middle grades, NCTM divides their content between 5 content standards: Number \& Operations, Algebra, Geometry, Measurement, and Data Analysis \& Probability. CCSSM content is divided between Ratio \& Proportional Relationships, The Number System, Expressions \& Equations, Geometry, and Statistics \& Probability. This could lead to some confusion. For example, standards from the measurement strand for NCTM have been placed in other strands or deleted altogether in CCSSM because there is no measurement strand in CCSSM for grades 6-8. Standards covered under Measurement for NCTM include conversions between metric and customary systems, area, perimeter, surface area and volume, formulas for finding areas of geometric shapes, and using scales to develop ratios and proportions. In CCSSM, converting measurements is covered under the Ratio \& Proportional Relationships strand number 3, (Use ratio and rate reasoning to solve real-world and 
mathematical problems). Area and volume are covered under the Geometry strand in CCSSM. The data Analysis and Probability strand in NCTM is fairly close to the Statistics \& Probability strand of the CCSSM. NCTM's standards are designed around collecting data and describing it as well as discussing probability of events. CCSSM discuss the same items, yet in less specific ways. NCTM provides specific content to teach (i.e., formulate questions, design studies, and collect data about a characteristic shared by two populations or different characteristics within one population), while the standard in CCSSM is stated briefly (recognize a statistical question as one that anticipates variability in the data related to the question and accounts for it in the answers $([15])$.

Some content occurs earlier in CCSSM. For examples, in elementary grades, by the end of grade 4, both documents expect students to understand the four basic operations with whole numbers, place value, and the meaning and uses of fractions. CCSSM require fluency (fast and accurate) in the addition, subtraction, and multiplication of fractions by the end of grade 5. Focal Points requires students to do this by the end of grade 6 . In middle grades, areas of overlap include the major hallmarks of algebra-proportionality, linear expressions and inequalities, and using equations and inequalities to solve real-life and mathematical problemswhich prepare students well for the more advanced mathematics they will face in high school. CCSSM require students to understand the role of transformations of geometric shapes on a coordinate plane, and in the area of probability, the CCSSM expect students to extend their knowledge of probability to compound events in grade 7, where the Focal Points does not.

\section{Final remarks}

Although it should be clear that adoption of the CCSSM standards is in no way mandatory, but pushed by the U.S. Department of Education with promises of more funding if states do things the government's way, CCSSM are supported by the federal government as if they are a "de facto" national curriculum standards. While most states have adopted CCSSM, some states have not. Recently, several states want to reverse their decision and un-adopt CCSSM. If a state adopted the CCSSM, it adopted 100\% of those standards. However, the state may 
add up to $15 \%$ more to the standards.

Changes occurring in mathematics education in the U.S. often make substantial influences on mathematics education world-wide. We wish that what we have presented here helps Korean educators and scholars better conceptualize a new era entering the U.S. mathematics education history, which is launched by the Common Core State Standards. This will be of particular interest to Korean mathematicians and mathematics educators who are or have been involved in developing a mathematics curriculum. In Korea, a new curricular guideline for school mathematics came out in 2009 and since then commercial publishers in collaboration with mathematicians, mathematics educators and mathematics teachers have started developing textbooks, claiming that their textbooks have been aligned with the new guideline. A teacher might think that he or she should not teach what is not in the standards for a particular grade. This is a prevalent myth that U.S. teachers have regarding the Common Core State Standards. As it might be true in Korean education communities, it is important to make it clear whether the new guideline has been created as standards or as a curriculum. Standards are not curriculum. Curriculum is a series of activities designed to help students achieve the standards and written curriculum is a piece of work with wisdom of practice. Teachers or curriculum developers may want to use some activities that enhance students understanding of previous topics that are covered under standards for earlier grades. They may want to use some activities that anticipate later topics that are covered under standards for later grades. Also, teacher support in implementing the guideline is crucial so that teachers can implement it in the way it is intended. Standards and curriculum guidelines are only documents until schools take advantage of it. Implementation is really everything. In the U.S., numerous workshops and forums for teachers and school administrators have taken place throughout the nation in order to help build an accurate, common understanding of their new standards. A means of assessment is being developed to accompany the implementation of CCSSM. The Korea's new curriculum guideline will be implemented in 2013, which is exciting. It will be even more exciting and rewarding when the guideline is implemented in the way that the developers intended it to be. 


\section{References}

[1] NCTM, Curriculum and evaluation standards for school mathematics, NCTM, Reston, VA. 1989.

[2] B. Means, C. Padilla, A. DeBarger, and M. Bakia. Implementing data-informed decision making in schools: Teacher access, supports and use, U.S. Department of Education, Office of Planning, Evaluation, and Policy Development, Policy and Program Studies Service. Washington, D.C. 2009.

[3] B. Reys. The intended mathematics curriculum as represented in state-level curriculum standards: Consensus or confusion?, Information Age Publishing, Inc. Charlotte, NC. 2006.

[4] Trends in International Mathematics and Science Study (TIMSS). International Association for the Evaluation of Educational Achievement. Amsterdam, The Netherlands. 1995.

[5] TIMSS. International Association for the Evaluation of Educational Achievement. Amsterdam, The Netherlands. 1999.

[6] TIMSS. International Association for the Evaluation of Educational Achievement. Amsterdam, The Netherlands. 2007.

[7] CCSSI. Career and college readiness, National Governors Association Center for Best Practices, Council of Chief State School Officers, Washington D.C. 2009.

[8] CCSSI. The Common Core State Standards for Mathematics, National Governors Association Center for Best Practices, Council of Chief State School Officers, Washington D.C. 2010.

[9] A. Ginsburg, S. Leinwand, and K. Decker. What the United States can learn from Singapore world-class mathematics system (and what Singapore can learn from the United States), American Institutes for Research. Washington, D.C. 2005.

[10] C.T. Cross, T.A. Woods, and S. Schweingruber. Mathematics learning in early childhood: Paths toward excellence and equity, National Research Council. Washington, D.C. 2009.

[11] J.W. Stigler and J. Hiebert, The teaching gap, Free Press, New York. 1999.

[12] NCTM. Principles and standards for school mathematics, NCTM. Reston, VA. 2000 .

[13] National Research Council. Adding it up: Helping children learn mathematics, National Academy Press. Washington, D.C. 2001.

[14] NCTM. Curriculum focal points for prekindergarten through grade 8 mathematics: A quest for coherence, NCTM. Reston, VA. 2006.

[15] NCTM. Making it happen: A guide to interpreting and implementing Common Core State Standards for Mathematics, NCTM. Reston, VA. 2011.

Department of Mathematics University of Northern Iowa Cedar Falls, IA 50614, USA E-mail: jihwa.noh@uni.edu 
Graduate School of Education

Kyonggi University

Suwon 443-760, Korea

E-mail: huhnan@kgu.ac.kr

Graduate School of Education

Ajou University

Suwon 443-749, Korea

E-mail: kohoh@ajou.ac.kr 